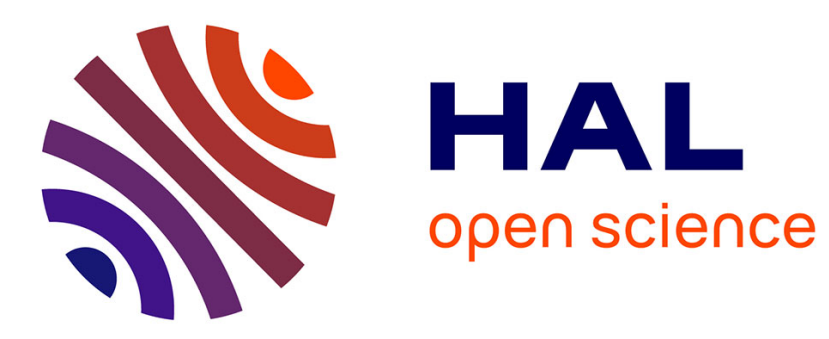

\title{
Screen-Space Curvature for Production-Quality Rendering and Compositing
}

Nicolas Mellado, Pascal Barla, Gael Guennebaud, Patrick Reuter, Gregory

Duquesne

\section{- To cite this version:}

Nicolas Mellado, Pascal Barla, Gael Guennebaud, Patrick Reuter, Gregory Duquesne. Screen-Space Curvature for Production-Quality Rendering and Compositing. SIGGRAPH Talk Program, Aug 2013, Anaheim, United States. hal-00813560v2

\section{HAL Id: hal-00813560 \\ https://hal.inria.fr/hal-00813560v2}

Submitted on 16 Apr 2013

HAL is a multi-disciplinary open access archive for the deposit and dissemination of scientific research documents, whether they are published or not. The documents may come from teaching and research institutions in France or abroad, or from public or private research centers.
L'archive ouverte pluridisciplinaire HAL, est destinée au dépôt et à la diffusion de documents scientifiques de niveau recherche, publiés ou non, émanant des établissements d'enseignement et de recherche français ou étrangers, des laboratoires publics ou privés. 


\title{
Screen-Space Curvature for Production-Quality Rendering and Compositing
}

\author{
Nicolas Mellado ${ }^{*} \quad$ Pascal Barla $^{1} \quad$ Gael Guennebaud $^{1} \quad$ Patrick Reuter $^{1} \quad$ Gregory Duquesne $^{2}$ \\ 1 - Inria - Univ. Bordeaux - IOGS - CNRS 2 - Luxology
}
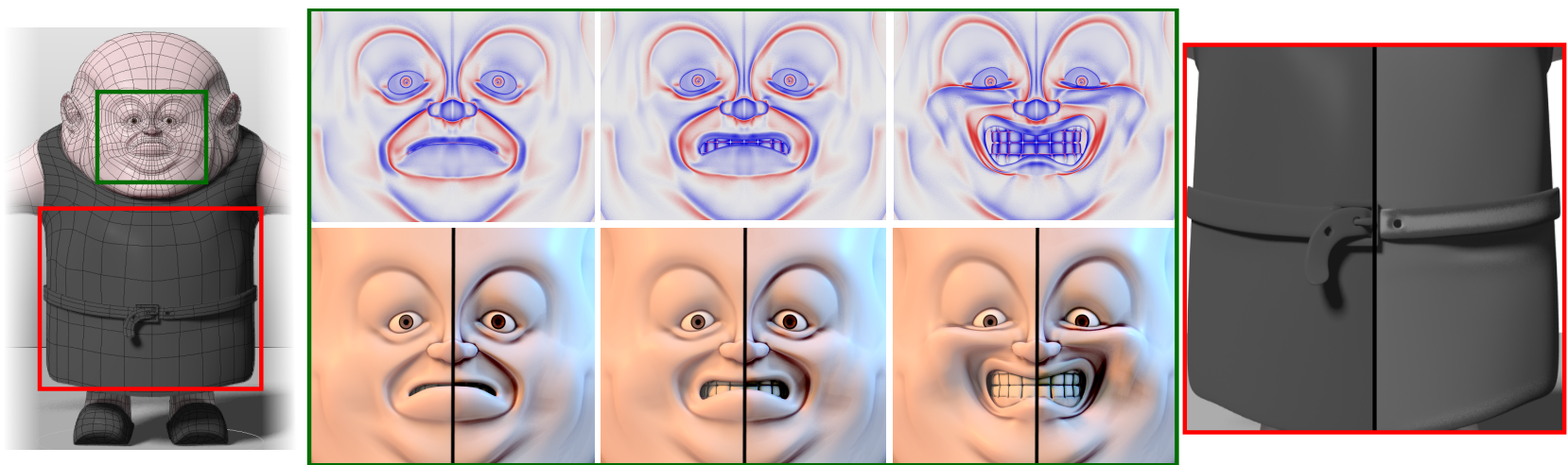

Figure 1: A subdivision surface character (3D model courtesy of Peter Eriksson) is animated and rendered using Modo (c) ray-tracing engine. Three poses are shown in the middle: our screen-space mean curvature (depicted on the top with concave regions in red, convex regions in blue) is used to modulate a basic shading (bottom-left) yielding an exaggerated appearance (bottom-right). The image on the right illustrates another shading modulation based on our offset measurement $\tau$.

\section{Introduction}

Surface curvature is a measure commonly employed in Computer Graphics for a vast range of applications: for modeling purposes of course, but also to drive texture generation, or to produce exaggerated or stylized shading results (see Figure 1).

Curvature is a differential property expressed at each surface point. When working with meshes, it can be efficiently computed per vertex using GPU-based techniques [Griffin et al. 2011]. However, this approach becomes impractical when dealing with production quality scenes that involve various representations (e.g., subdivision surfaces, implicit and procedural geometry, displacement and bump maps) and/or deformable objects. This severely limits its use in real-time editing (as in sculpting) or for shading animated scenes.

\section{Screen-Space Curvature}

Our approach may be applied either in ray-tracing or compositing contexts. For each sample (ray or pixel), we start by collecting neighbor samples in screen-space that are closer than a threshold distance $t$. We also reject neighbors that are farther than a threshold relative depth $d$, to avoid collecting samples across occluding contours. We then recover a normal vector and a $3 \mathrm{D}$ position for each neighbor sample. The resulting local point cloud is fit with an algebraic sphere where each sample is weighted by a compactlysupported function parametrized by $t$.

Our fitting is performed using the method of Mellado et al. [2012], which has the benefit of characterizing the resulting sphere with geometrically-meaningful parameters. This provides us not only with a mean curvature estimate $\kappa$, but also with an offset $\tau$ that identifies local relief and a smooth reconstructed normal vector $\boldsymbol{\eta}$. With this approach, $t$ controls the scale of the local reconstruction. As shown in Figure 2, our approach produces an accurate approximation of object-space mean curvature, which is due to the local nature of differential properties. There is a notable difference though: farther objects exhibit less details than closer ones with the screenspace approach, which provides for automatic simplification and reduced aliasing artifacts.

\footnotetext{
*e-mail:nicolas.mellado@inria.fr
}

An alternative to our screen-space curvature would be to apply 2D derivative filters on normals [Vergne et al. 2009]. However, this approach neglects 3D positions, and raises issues nearby occluding contours, whereas our fitting remains well-defined.
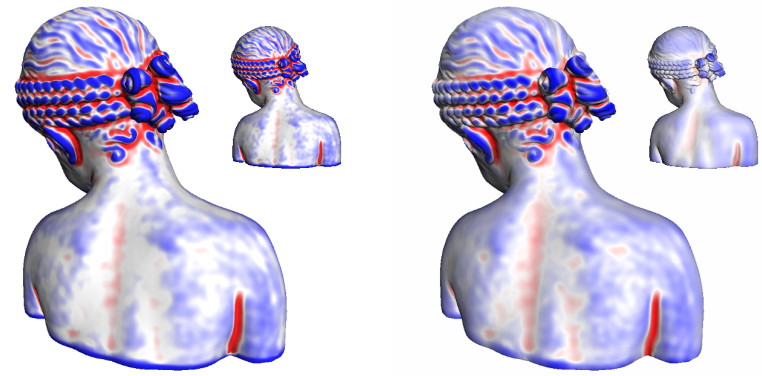

Figure 2: Comparison between mean curvature estimated in object- (left) and screen-space (right), shown at 2 different scales.

\section{Applications}

We have implemented SSC in Modo (c) on top of its ray-tracing engine, and in CUDA for post-processing, as shown in the accompanying video. An example animation is depicted in Figure 1, where we visualize our mean curvature estimate $\kappa$ with a color code, along with a simple curvature-based shading result. Our method is applied at each frame with a negligible performance overhead compared to rendering (for both pixel- and ray-based implementations), and it exhibits natural temporal coherence.

In future work, we plan to use SSC during sculpting to enhance small (yet important) surface details, and for non-photorealistic rendering to guide stylization. In both cases, we believe that not only $\kappa$ but also $\tau$ and $\boldsymbol{\eta}$ will prove to be valuable control parameters.

\section{References}

GrifFin, W., WANG, Y., BerRios, D., AND Olano, M. 2011. GPU curvature estimation on deformable meshes. In ACM I3D '11, 159-166.

Mellado, N., Guennebaud, G., Barla, P., Reuter, P., and Schlick, C. 2012. Growing least squares for the analysis of manifolds in scale-space. Computer Graphics Forum 31, 5, 1691-1701.

Vergne, R., Pacanowski, R., Barla, P., Granier, X., and Schlick, C. 2009. Light warping for enhanced surface depiction. ACM Trans. on Graph. 28, 3. 